\title{
Total ginsenosides of Chinese ginseng induces cell cycle arrest and apoptosis in colorectal carcinoma HT-29 cells
}

\author{
TING LI ${ }^{1}$, WAN SUN $^{2}$, XIAOQIAO DONG ${ }^{3}$, WENHUA YU $^{3}$, JIANYONG CAI $^{4}$, \\ QIANG YUAN $^{1}$, LETIAN SHAN ${ }^{2}$ and THOMAS EFFERTH ${ }^{4,5}$ \\ ${ }^{1}$ Second Clinical Medical College; ${ }^{2}$ The First Affiliated Hospital, Zhejiang Chinese Medical University, Hangzhou, \\ Zhejiang 310053; ${ }^{3}$ Department of Neurosurgery, Hangzhou First People's Hospital, Hangzhou, Zhejiang 310006; \\ ${ }^{4}$ Department of Neurosurgery, Wenzhou Central Hospital, Wenzhou, Zhejiang 325000, P.R. China; \\ ${ }^{5}$ Department of Pharmaceutical Biology, Institute of Pharmacy and Biochemistry, \\ Johannes Gutenberg University, D-55128 Mainz, Germany
}

Received December 15, 2017; Accepted July 5, 2018

DOI: $10.3892 / \mathrm{ol} .2018 .9192$

\begin{abstract}
Colorectal carcinoma (CRC) is the most frequent malignant disease of the gastrointestinal tract and it has a poor prognosis. The current treatment options for CRC are far from optimal; they have limited efficacy and toxic effects. Chinese ginseng (the dried root of Panax ginseng) is a medicinal herb, of which ginsenosides are the most effective anticancer component. The aim of the present study was to evaluate the anti-CRC effect of total ginsenosides of Chinese ginseng (TGCG), by analyzing the cellular and molecular pathways. This was done via MTT assay, morphological observation (DAPI staining), flow cytometry for cell cycle and apoptosis analyses, reverse transcription-quantitative polymerase chain reaction and western blot analysis. The results revealed that TGCG inhibited cell proliferation and induced cell cycle arrest and cell apoptosis in HT-29 cells in a dose-dependent manner. The mRNA expression of $C D K 2, C D K 4, C D K 6, B A X, C D K N 2 B, C A S P 8$, CASP3, TP53, TOP1, MYC, MDM2, and CCND1 and the protein expression of cyclin-dependent kinase (Cdk) 2, Cdk4, Cyclin D1, Bax, p21 ${ }^{\text {WAF1 }}$, p2 $7^{\text {Kipl }}$, c-Myc, p1 $5^{\text {INK4b }}$, and p53 were revealed to be modulated by TGCG in HT-29 cells, and are all factors associated with DNA damage, cell proliferation, cell cycle and apoptosis. In conclusion, TGCG induced cell cycle arrest at the $\mathrm{G}_{0} / \mathrm{G}_{1}$ and $\mathrm{G}_{2} / \mathrm{M}$ phases and induced apoptosis in HT-29 cells through the c-Myc- and p53-mediated signaling
\end{abstract}

Correspondence to: Professor Qiang Yuan, Second Clinical Medical College, Zhejiang Chinese Medical University, 548 Binwen Road, Binjiang, Hangzhou, Zhejiang 310053, P.R. China E-mail: yuanqiang0825@sina.com

Dr Letian Shan, The First Affiliated Hospital, Zhejiang Chinese Medical University, 548 Binwen Road, Binjiang, Hangzhou, Zhejiang 310053, P.R. China

E-mail: letian.shan@hotmail.com

Key words: colorectal carcinoma, HT-29 cells, total ginsenosides of Chinese ginseng, c-Myc, p53 pathways, possibly in response to DNA damage. Therefore, TGCG may be regarded a promising candidate for development as an anticancer agent for the treatment of CRC.

\section{Introduction}

On account of the deteriorating living environment and unfavorable living habits, cancer becomes the leading cause of human mortality around the world (1). Among all cancers, colorectal carcinoma (CRC) is the most frequent malignant disease of the gastrointestinal tract and responsible for 600,000 deaths annually worldwide (2). It develops as the third most common cancer in men (746,000 cases, $10 \%$ of all cancers) and the second most common cancer in women (614,000 cases, $9.2 \%$ of all cancers) (2). More than $50 \%$ of all CRC cases occur in more developed regions, e.g., 345,000 new cases and 152,000 deaths were reported in the European Union (3). In some regions with previously low incidence rates, e.g., Eastern Europe and East Asia, significantly increasing numbers of CRC cases have been noted and attributed to changes in risk factors and diet towards a lifestyle common to Western countries (4). The individual risk of CRC is essentially dependent on non-modifiable dispositional factors such as age, sex, and family history as well as in principle modifiable exposure to risk factors (3). Up to one-third of the CRC risk may be attributable to hereditary factors, and another $30 \sim 50 \%$ of the CRC risk is attributable to lifestyle factors such as smoking, high consumption of red and processed meat, obesity, diabetes, and excessive consumption of alcohol (5).

Sadly enough, the prognosis of CRC patients is especially poor: Roughly two-third of CRC has been detected in an inoperable, advanced stage, when the first clinical signs occur (6). The current mainstay of treatment for CRC is surgical resection with chemotherapy and radiotherapy (7). Unfortunately, to date, the therapies are far from optimal due to their limited efficacy as well as toxic effects (8). For example, chemotherapeutic regimens are always involved in delivering the drug to both tumor and normal tissue, resulting in unexpected toxic effects such as neutropenia, anemia, hand-foot syndrome, diarrhea, gastrointestinal toxicity, 
mucositis, nausea, vomiting, fatigue, hematological disorders and liver toxicity (9). The adverse events not only worsen the patients' quality of life, but rather, cause patients to refuse further chemotherapy (10). Therefore, the need to develop more effective and safe agents for CRC treatment is urgent. In recent years, a growing interest has arisen for the therapeutical potential of natural resources to discover new anticancer agent, which is promising to provide a favorable option for CRC patients (11-14).

Traditional Chinese medicine (TCM) becomes a popular complementary and alternative medicine for cancer treatment in clinic. By using herbal medicines, TCM shows more therapeutic benefits but lesser side effect and cost than the conventional chemotherapeutics (15). As one of the most famous TCM, Chinese ginseng (the dried root of Panax ginseng C.A. Mey.) has been used for over 2,000 years as a medicine in China and is popularly used in more than 35 countries as food, health supplement, and natural remedy (16). It is claimed to be effective in treating cancer, including CRC (17). Many components are responsible for the anti-CRC effect of Chinese ginseng, including protopanaxadiol, $\mathrm{Rg} 1, \mathrm{Rb} 1, \mathrm{Rg} 3, \mathrm{Rh} 2$, and compound $\mathrm{K}$. Protopanaxadiol is an active ginseng metabolite that can enhance the anticancer effect of chemotherapy on CRC (18). Ginsenoside compounds, Rg1, Rb1, Rg3, and Rh2, have been found to possess anti-CRC effect by inducing cell apoptosis and cell cycle arrest and inhibiting metastasis (19-22). Besides, ginsenoside compound $\mathrm{K}$ possesses not only anti-proliferative and pro-apoptotic effect but also synergistic activity with cancer cell-specific apoptosis-inducing cytokine on CRC (23). Therefore, ginsenoside compounds are a kind of ginseng component possessing anticancer effect on CRC. This study focused on total ginsenosides (combination of ginsenoside compounds) of Chinese ginseng and evaluated its effect on CRC cells from the cellular and molecular levels.

\section{Materials and methods}

Chemicals and reagents. Powders of total ginsenosides of Chinese ginseng (TGCG) (S25997; $>80 \%$ of purity), ginsenoside Rb1 (Rb1) (B21050; $>98 \%$ of purity), ginsenoside Re (Re; B21055; >98\% of purity), ginsenoside Rd (Rd; B21054; $>98 \%$ of purity), and ginsenoside $\operatorname{Rg} 1$ (Rg1) (B21057; >98\% of purity) were obtained from Shanghai Yuanye Biotechnology Co., Ltd (Shanghai, China; batch no. 2016Y08016). RPMI-1640 medium, fetal bovine serum (FBS), and $0.25 \%$ trypsin were obtained from Gibco; Thermo Fisher Scientific, Inc. (Waltham, MA, USA). 3-(4,5-dimethylthiazol-2-yl)-2,5-diphenyltetrazolium bromide (MTT) and dimethyl sulfoxide (DMSO) were obtained from Sigma-Aldrich; Merck KGaA (Darmstadt, Germany). Annexin V:FITC apoptosis detection kit and cell cycle kit were purchased from BD Biosciences, (Franklin Lakes, NJ, USA). ProLong ${ }^{\circledR}$ Diamond Antifade Mountant with DAPI was purchased from Invitrogen; Thermo Fisher Scientific, Inc. All antibodies were purchased from Cell Signaling Technology Inc. (CST; Danvers, MA, USA). RNAiso Plus kit for real time PCR was purchased from Takara (Dalian, China).

Chemoprofile analyses. The HPLC analysis was performed on an Agilent 1260 Infinity system (Agilent Technologies,
Inc., Santa Clara, CA, USA). Chromatographic separation was achieved on a Hypersil BDS-C18 column (250x4.6 mm, $5 \mu \mathrm{m}$; Shandon Scientific, Cheshire, UK) at temperature of $30^{\circ} \mathrm{C}$. The mobile phase consisted of (A) acetonitrile and (B) $0.1 \%$ phosphoric acid solution with flow rate of $1.3 \mathrm{ml} / \mathrm{min}$. Samples were eluted with a gradient elution system at $0 \sim 30 \mathrm{~min}$ (19\% A), 30 35 $\min (19 \sim 24 \% \mathrm{~A})$, and 35 60 $\min (24 \sim 60 \% \mathrm{~A})$. The sample injection volume was $10 \mu \mathrm{l}$ and the detection wavelength was $205 \mathrm{~nm}$. The data was analyzed to determine the contents of Rb1, Re, Rd, and Rg1 in TGCG.

Cell line and culture. Human CRC cell lines (HT-29, HCT-116, and SW620) were obtained from Shanghai Cell Bank of Chinese Academy of Sciences (Shanghai, China) and cultured in RPMI-1640 medium containing $10 \% \mathrm{FBS}$ at $37^{\circ} \mathrm{C}$ in a humidified $5 \% \mathrm{CO}_{2}$ incubator. The medium was changed daily and the cells were treated in their logarithmic growth phase.

MTT assay. MTT assay was performed to evaluate the cell viability of HT-29, HCT-116, and SW620 cells. Cells were seeded on 96 -well plates with density of $5 \times 10^{3}$ cells/well in $200 \mu \mathrm{l}$ medium for $24 \mathrm{~h}$ and then treated with TGCG at different concentrations $(0,25,50,100,200,400 \mu \mathrm{g} / \mathrm{ml})$ for $24 \mathrm{~h}$ (all cell lines), $48 \mathrm{~h}$ (HT-29), and $72 \mathrm{~h}$ (HT-29). Each $20 \mu \mathrm{l}$ MTT solution $(5.0 \mathrm{mg} / \mathrm{ml})$ was added to each well and incubated at $37^{\circ} \mathrm{C}$ for $4 \mathrm{~h}$. Then $150 \mu \mathrm{l}$ DMSO was added in each well to dissolve the MTT formazan crystals and the optical density (OD) value was measured at $490 \mathrm{~nm}$ with a microplate reader (Bio-Rad Laboratories, Inc., Hercules, CA, USA). Inhibitory rate $(\%)=[1-(\mathrm{TB}-$ treated OD/untreated OD) $] \times 100 \%$. The $50 \%$ inhibitory concentrations $\left(\mathrm{IC}_{50}\right)$ for 24,48 , and $72 \mathrm{~h}$ were calculated by regression analysis, respectively.

Cell morphology and DAPI staining. HT-29 cells were seeded on 6 -well plates with density of $3 \times 10^{5}$ cells/well for $24 \mathrm{~h}$, followed by TGCG treatment at low, medium, and high doses for $24 \mathrm{~h}$. The cells were harvested and washed with PBS thrice and then fixed with $4 \%$ paraformaldehyde in PBS for 30 min at room temperature. Then the cells were permeabilized with $0.5 \%$ Triton X-100 in PBS for $10 \mathrm{~min}$. An aliquot of the cells were mounted using ProLong ${ }^{\circledR}$ Diamond Antifade Mountant (Thermo Fisher Scientific, Inc.) with DAPI for 3 min in dark and then washed thrice. The unstained and stained cells were observed under a fluorescence microscope (Carl Zeiss, Göttingen, Germany). Five coverslips were used as replicates of each group and the apoptotic nuclei of cells were visualized.

Flow cytometry. TGCG-induced apoptosis of HT-29 cells was determined by flow cytometry using an Annexin V/PI method, according to the manufacturer's protocol. Briefly, HT-29 cells were seeded on 6 -well plates with density of $3 \times 10^{5}$ cells/well for $24 \mathrm{~h}$ and then were treated with TGCG at low, medium, and high doses for another $24 \mathrm{~h}$. Thereafter, the cells were harvested and washed twice with cold PBS, and then labeled with FITC Annexin V and PI in binding buffer. Fluorescence intensity of the cells was detected by BD FACSVerse ${ }^{\mathrm{TM}}$ flow cytometer (BD Biosciences). The apoptosis rate (\%) for each treatment was calculated.

Cell cycle analysis was also performed by flow cytometry using BD cell cycle kit (BD Biosciences). HT-29 cells were 
Table I. Primer sequences used for quantitative polymerase chain reaction analysis.

\begin{tabular}{lll}
\hline \multicolumn{1}{c}{ Gene } & \multicolumn{1}{c}{ Forward primer } & \multicolumn{1}{c}{ Reverse primer } \\
\hline$\beta$-actin & 5'-CATGTACGTTGCTATCCAGGC-3' & 5'-CTCCTTAATGTCACGCACGAT-3' \\
$C A S P 3$ & 5'-AGAACTGGACTGTGGCATTGAG-3' & 5'-GCTTGTCGGCATACTGTTTCAG-3' \\
$C A S P 8$ & 5'-CTCCCCAAACTTGCTTTATG-3' & 5'-AAGACCCCAGAGCATTGTTA-3' \\
$C C N D 1$ & 5'-CAATGACCCCGCACGATTTC-3' & 5'-CATGGAGGGCGGATTGGAA-3' \\
$C D K N 2 A$ & 5'-CATGGTGCGCAGGTTCTTG-3' & 5'-CGGGATGTGAACCACGAAA-3' \\
$C D K N 2 B$ & 5'-AACACAGAGAAGCGGATTTC-3' & 5'-AGGTCCAGTCAAGGATTTCA-3' \\
$C D K 2$ & 5'-GCTAGCAGACTTTGGACTAGCCAG-3' & 5'-AGCTCGGTACCACAGGGTCA-3' \\
$C D K 4$ & 5'-AAATCTTTGACCTGATTGGG-3' & 5'-CCTTATGTAGATAAGAGTGCTG-3' \\
$C D K 6$ & 5'-CTGAATGCTCTTGCTCCTTT-3' & 5'-AAAGTTTTGGTGGTCCTTGA-3' \\
$M D M 2$ & 5'-ACCTCACAGATTCCAGCTTCG-3' & 5'-TTTCATAGTATAAGTGTCTTTTT-3' \\
$M Y C$ & 5'-GCCACGTCTCCACACATCAG-3' & 5'-TGGTGCATTTTCGGTTGTTG-3' \\
$T O P 1$ & 5'-TCCGGAACCAGTATCGAGAAGA-3' & 5'-CCTCCTTTTCATTGCCTGCTC-3' \\
$T P 53$ & 5'-TCAACAAGATGTTTTGCCAACTG-3' & 5'-ATGTGCTGTGACTGCTTGTAGATG-3'
\end{tabular}

seeded on 6-well plates with density of $3 \times 10^{5}$ cells/well for $24 \mathrm{~h}$ and then were treated with TGCG at low, medium, and high doses for another $24 \mathrm{~h}$. The cells were harvested and washed with PBS thrice and then were stained with PI/RNase staining solution in accordance with the manufacturer's protocol of BD cell cycle kit (BD Biosciences).

Reverse transcription-quantitative polymerase chain reaction $(R T-q P C R)$ analysis. Relative mRNA expressions of targeted genes in HT-29 cells were detected by qPCR assay on an ABI QuantStudio ${ }^{\text {TM }} 7$ Flex Real-Time PCR System (Applied Biosystems; Thermo Fischer Scientific, Inc.). The total RNA of the cells in each group was extracted using TRIzol reagent and synthesized to cDNA via RT. PCR reaction system had a $20.0 \mu 1$ volume: $10.0 \mu 1 \mathrm{SYBR}^{\circledR}$ Premix Ex Taq II (Tli RnaseH Plus), 0.8 $\mu$ 1 PCR Forward Primer, $0.8 \mu 1$ PCR Reverse Primer, 2.0 $\mu 1$ template cDNA, 0.4 $\mu 1$ ROX

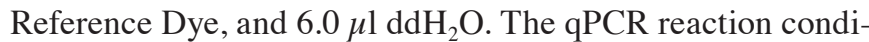
tion was set to $95^{\circ} \mathrm{C}$ for $30 \mathrm{sec}$ initial denaturation, 40 cycles of $95^{\circ} \mathrm{C}$ for $5 \mathrm{sec}$ denaturation, $60^{\circ} \mathrm{C}$ for $34 \mathrm{sec}$ annealing, and $72^{\circ} \mathrm{C}$ for $40 \mathrm{sec}$ extension. At the end of each reaction, a melting curve analysis was performed. $\beta$-actin was used as the reference gene and $2^{-\Delta \Delta C T}$ method was applied to analyze the relative mRNA expressions (Table I).

Western blot analysis. The total proteins of the TH-29 cells $\left(1.5 \times 10^{6}\right)$ were extracted using a lysis buffer $(50 \mathrm{mM}$ Tris- $\mathrm{HCl}$, $\mathrm{pH} 7.4,150 \mathrm{mM} \mathrm{NaCl}, 1 \mathrm{mM}$ EDTA, $1 \%$ Triton, $0.1 \%$ SDS) with proteinase inhibitor cocktail (Bimake, Houston, TX, USA) for $30 \mathrm{~min}$ on ice. The proteins were separated by a denaturing sodium dodecyl sulfate polyacrylamide gel electrophoresis (SDS-PAGE; 6-12\%) and then transferred onto a nitrocellulose membrane (Sartorius Stedim, Goettingen, Germany). The membrane was blocked with 5\%non-fat milk for $2 \mathrm{~h}$, followed by overnight incubation at $4^{\circ} \mathrm{C}$ with the primary antibodies [Bax, cyclin-dependent kinase (Cdk2), Cdk4, c-Myc, Cyclin D1, p15 ${ }^{\text {INK4b }}$, p2 $1^{\text {WAF1 }}$, p2 $7^{\text {Kip1 }}$, p53]. Following inculation with peroxidase-conjugated goat anti-rabbit/mouse IgG at room temperature for $2 \mathrm{~h}$, proteins were visualized using
Western Lightning ${ }^{\circledR}$ Plus ECL (Perkin Elmer, Waltham, MA, USA) and detected using X-film (Kodak, Tokyo, Japan) and scanned.

Statistical analysis. Data were expressed as mean \pm SD and subjected to one-way analysis of variance, followed by Fisher's least significant difference comparison. All analyses were performed using an updated version of DPS software (24). $\mathrm{P}<0.05$ was considered to indicate a statistically significant difference.

\section{Results}

The anti-proliferative effect of TGCG on CRC cells were determined by MTT assay. As shown in Fig. 1A, TGCG obviously inhibited the cell viability of HT-29 at a dose range of 25 to $400 \mu \mathrm{g} / \mathrm{ml}$ and a time range of 24 to $72 \mathrm{~h}$. The inhibitory effect was increased with increasing TGCG doses at each time point and also with increasing time period at almost each dose point, indicating a time- and dose-dependent manner of TGCG. The $\mathrm{IC}_{50}$ values were $395.79,124.63$, and $105.21 \mu \mathrm{g} / \mathrm{ml}$ for 24,48 and $72 \mathrm{~h}$ treatment, respectively. We employed 50, 100, and $200 \mu \mathrm{g} / \mathrm{ml}$ as low, medium, and high doses of TGCG at $24 \mathrm{~h}$ for the following assays. As compared with the inhibitory effects on HCT-116 and SW620, TGCG showed a stronger effect on HT-29 (Fig. 1B).

The inhibitory effect of TGCG on TH-29 cells at morphological level was observed with DAPI staining by fluorescence microscopy. As shown in Fig. 1C, detached cells in round and shrunken shape were seen with TGCG treatment under light microscope (indicated by arrows). DAPI staining showed typical apoptotic signs on TGCG-treated cells, such as chromatin condensation, karyopyknosis and nuclear fragmentation (indicated by arrows), indicating cell apoptosis induced by TGCG.

HPLC analysis showed the chemoprofile of TGCG comprising Rb1, Rd, Re, and Rg1 (Fig. 2A). The contents of $\mathrm{Rb} 1, \mathrm{Rd}, \mathrm{Re}$, and Rg1 in TGCG are $85.23 \pm 0.65,97.50 \pm 1.93$, $153.67 \pm 1.15$, and $71.27 \pm 0.50 \mu \mathrm{g} / \mathrm{mg}$, respectively (Fig. 2B). 

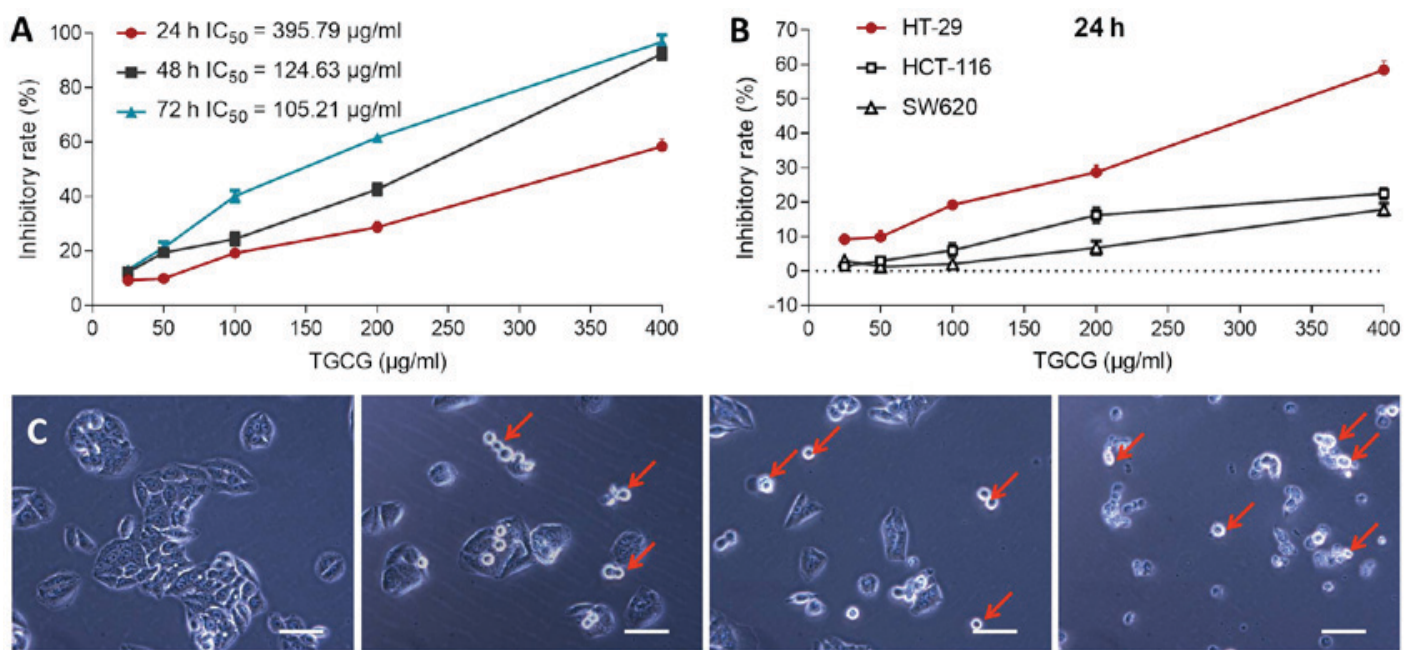

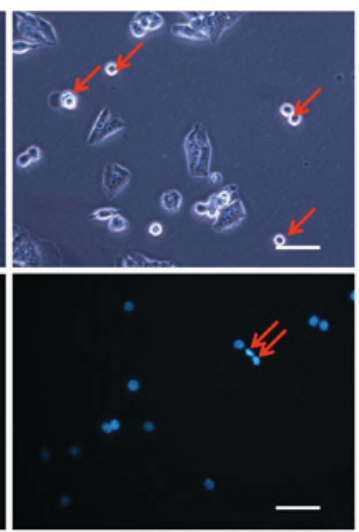

$100 \mu \mathrm{g} / \mathrm{ml}$

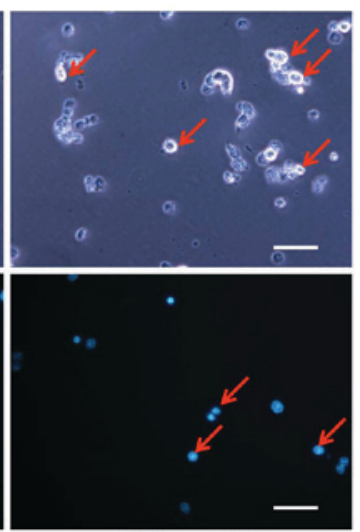

$200 \mu \mathrm{g} / \mathrm{ml}$

Figure 1. (A) cell viability of HT-29 cells following TGCG treatment at 24, 48 and $72 \mathrm{~h}$. (B) Cell viability of HT-29, HCT-116 and SW620 cells following TGCG treatment at 24 h. (C) Morphological observation (light microscope and fluorescence microscope) of HT-29 cells following TGCG treatment. Values are presented as the mean \pm standard deviation, $\mathrm{n}=5$. The red arrows indicate apoptotic cells. Scale bar, $60 \mu \mathrm{m}$. TGCG, total ginsenosides of Chinese ginseng.
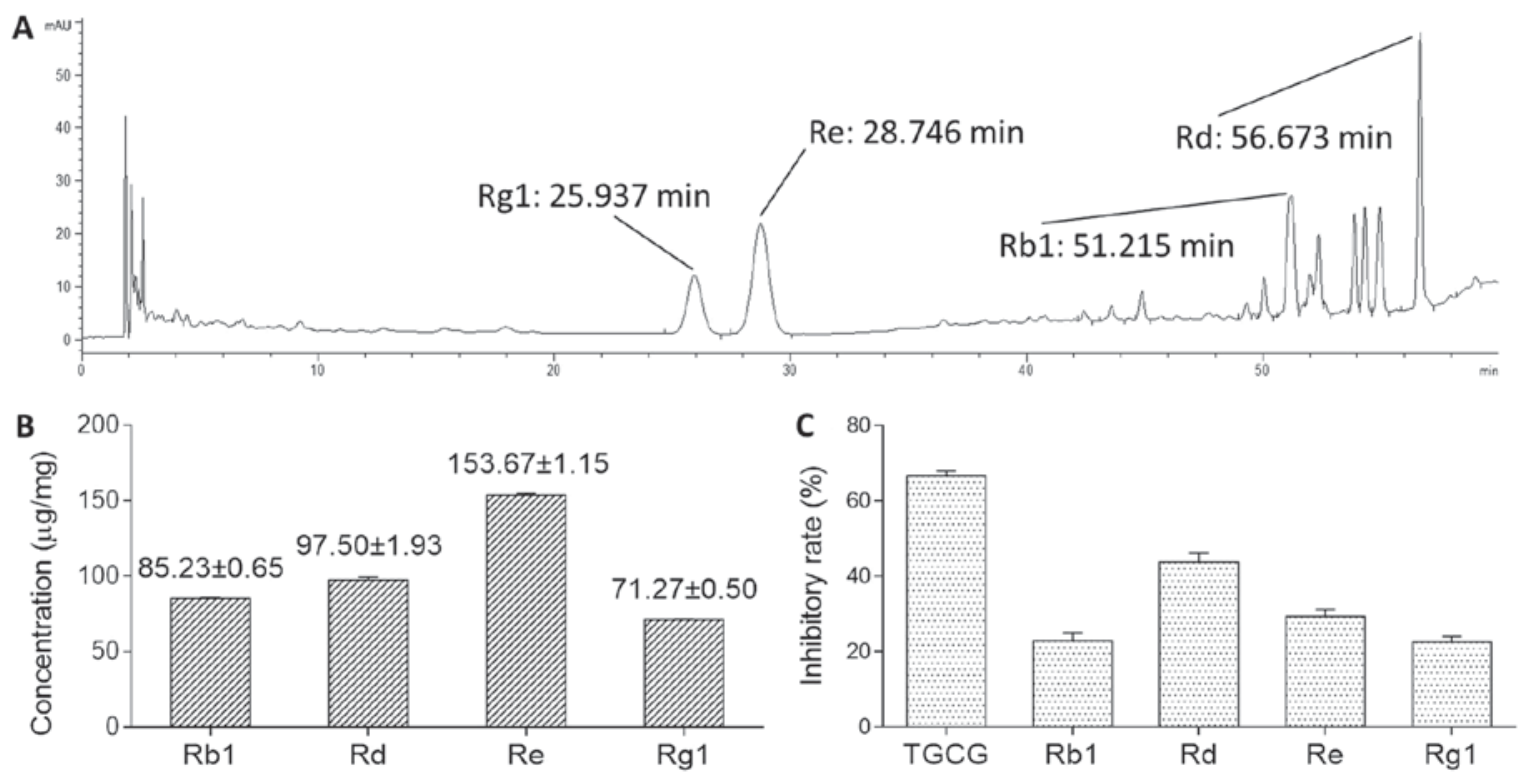

Figure 2. (A) HPLC chemoprofile and (B) concentrations of TGCG and its ginsenoside components. (C) Cell viability of HT-29 cells treated with TGCG, Rb1, $\mathrm{Rd}, \mathrm{Re}$, and $\mathrm{Rg} 1$ at $400 \mu \mathrm{g} / \mathrm{ml}$ for $24 \mathrm{~h}$. TGCG, total ginsenosides of Chinese ginseng.

MTT assay indicated that TGCG at $400 \mu \mathrm{g} / \mathrm{ml}$ exerted stronger inhibitory effect than that of its ginsenoside component on HT-29 cells after $24 \mathrm{~h}$ treatment (Fig. 2C).

The apoptosis-inducing effect of TGCG on HT-29 cells was further studied by Annexin V-FITC/PI double staining assay using flow cytometry. As shown in Fig. 3, early and late apoptosis increased progressively from 1.27 to $66.45 \%$ with treatment of increasing doses of TGCG from 0 to $200 \mu \mathrm{g} / \mathrm{ml}$, indicating a dose-dependent manner. Particularly, TGCG upon $100 \mu \mathrm{g} / \mathrm{ml}$ primarily induced early apoptosis $(42.15 \%)$ in HT-29 cells.

The effect of TGCG on HT-29 cell cycle progression was performed by flow cytometry. As shown in Fig. 4, after $24 \mathrm{~h}$ treatment on HT-29 cells, TGCG induced obvious $\mathrm{G}_{0} / \mathrm{G}_{1}$ phase accumulation and $\mathrm{S}$ phase depletion in a dose-dependent manner. A visible increase of cell number in $\mathrm{G}_{2} / \mathrm{M}$ phase was also found with TGCG treatment. These trends indicated that TGCG could induce cell cycle arrest in HT-29 cells. 

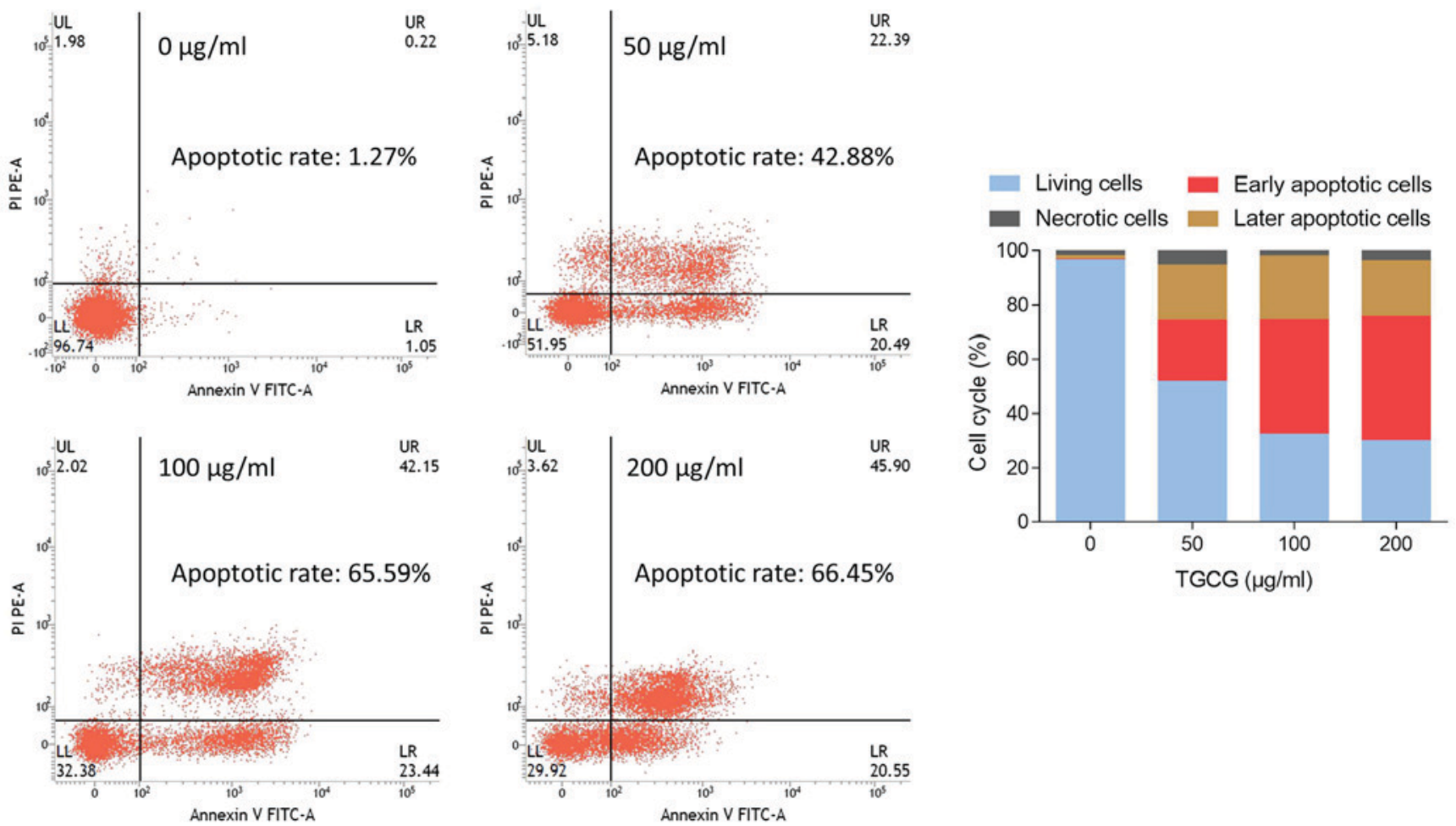

Figure 3. Flow cytometry analysis of HT-29 cell apoptosis following TGCG treatment by double staining with Annexin V-fluorescein isothiocyanate and propidium iodide. TGCG, total ginsenosides of Chinese ginseng.

The regulatory effect of TGCG on the relative expression of target genes in HT-29 cells was determined by qPCR assay. As shown in Fig. 5, with $24 \mathrm{~h}$ treatment, $T G C G$ could significantly downregulate the expression of $C D K 2, C D K 4, C D K 6, T O P 1$, $M Y C, M D M 2$, and $C C N D 1 \mathrm{mRNA}$ transcripts and upregulate the expression of $B A X, C D N K 2 B, C A S P 8, C A S P 3$, and TP53 mRNA transcripts in HT-29 cells as compared to the untreated group. In most cases, TGCG induced a dose-dependent manner in the mRNA modulation.

The regulatory effect of TGCG on protein expression of HT-29 cells was determined by western blot assay. Proteins related to cell apoptosis and cell cycle were analyzed by different experiments under the same condition and the control ( $\beta$-tubulin) was found similarly expressed in each experiment. The expression profiles of tested proteins were assembled together in Fig. 6 with one representative control. With $24 \mathrm{~h}$ treatment, TGCG could significantly downregulate the expression of cell cycle checkpoint proteins $(\mathrm{Cdk} 2, \mathrm{Cdk} 4$, and Cyclin D1) and upregulate the expression of cell apoptosis- and cell cycle related proteins (Bax, p21 ${ }^{\mathrm{WAF} 1}, \mathrm{p} 27^{\mathrm{Kip} 1}$, $\mathrm{c}-\mathrm{Myc}, \mathrm{p} 15^{\mathrm{INK} 4 \mathrm{~b}}$, and $\mathrm{p} 53$ ) as compared to the untreated group.

\section{Discussion}

An epidemiological survey on 1,000 subjects revealed reduced risks of various cancers, including $\mathrm{CRC}$, in those who received ginseng, when compared with those who did not use it (25). Many studies have been conducted on the anti-CRC effects of ginseng from its crude extracts to single components. For instance, both fermented ginseng extract and ginseng polysaccharide fraction showed anti-proliferative and anti-invasive effects on HT-29 cells (26). A steamed extract of ginseng root induced mitochondrial damage and cell apoptosis by producing reactive oxygen species (ROS) in CRC cells (27). As a main component of ginseng, ginsenoside has been shown to exert strong anticancer activity by blocking cell cycle progression at $\mathrm{G}_{1}$ phase or $\mathrm{G}_{1} / \mathrm{S}$ boundary in breast and liver cancer cells through activation of $\mathrm{p} 21^{\mathrm{WAF} 1}, \mathrm{p} 27^{\mathrm{Kip} 1}$, and $\mathrm{p} 53$ (28-30). It can also induce cancer cell apoptosis by altering mitochondrial membrane integrity, releasing cytochrome $c$, and activating caspase proteases $(31,32)$. Nevertheless, little report has determined whether ginsenoside has anti-CRC effect.

In this study, TGCG arrested cell cycle of CRC cells at $\mathrm{G}_{0} / \mathrm{G}_{1}$ and $\mathrm{G}_{2} / \mathrm{M}$ phases by inhibiting cell cycle activators (c-Myc, Cdk2, Cdk4, Cdk6, and Cyclin D1) and activating cell cycle inhibitors (p15 $5^{\mathrm{INK} 4 \mathrm{~b}}, \mathrm{p} 21^{\mathrm{WAF} 1}$, and $\left.\mathrm{p} 27^{\mathrm{Kip} 1}\right)$. Since Cdk2, Cdk4, Cdk6, Cyclin D1, p15 ${ }^{\mathrm{INK} 4 \mathrm{~b}}, \mathrm{p} 21^{\mathrm{WAF} 1}$, and p27 $7^{\mathrm{Kip} 1}$ could be encoded by the downstream genes of c-Myc, TGCG was concluded to induce cell cycle arrest through a c-Myc-mediated mechanism (33-35). Cyclin D1 and c-Myc are the downstream targets of Wnt/ $\beta$-catenin signaling pathway, the inhibition of which causes suppression of tumor growth, epithelial mesenchymal transition (EMT), and cell motility of CRC (36). Besides, c-Myc, Cyclin D1, Cdk2, and Cdk4 are also the downstream cell cycle factors of PI3K/Akt signaling pathway in CRC, while p21 and p27 are its downstream cell cycle inhibitors $(37,38)$. Furthermore, c-Myc and Cyclin D1 are cell proliferative effectors in the downstream of NF- $\mathrm{KB}$ signaling pathway in CRC (39). Therefore, Wnt/ $\beta$-catenin, PI3K/Akt, and NF- $\kappa \mathrm{B}$ signaling pathways might possibly participate in the action mechanism of TGCG underlying the observed effect on cell cycle and proliferation of CRC. It has been reported that ginseng extract could enhance the anti-proliferative effect of 5-fluorouracil (5-FU) on CRC cells 

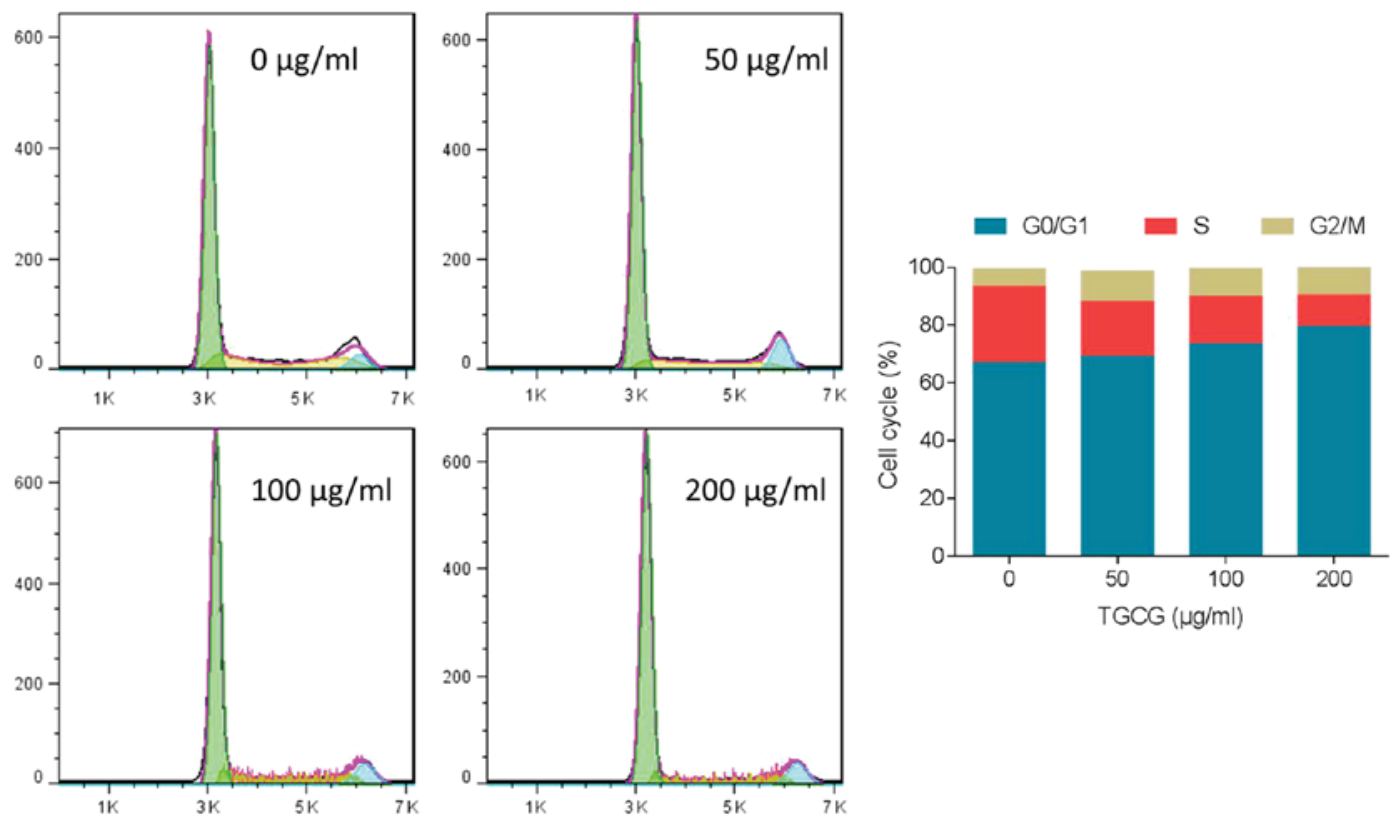

Figure 4. Flow cytometry analysis of HT-29 cell cycle progression following TGCG treatment. TGCG, total ginsenosides of Chinese ginseng.

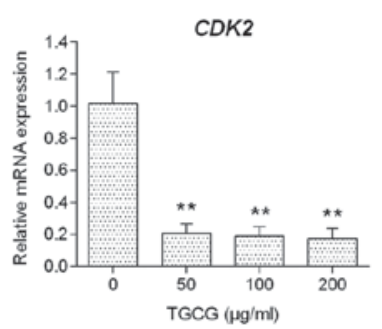

TOP1

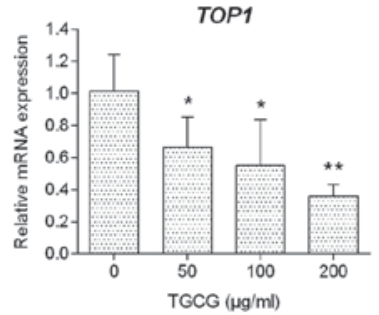

TP53

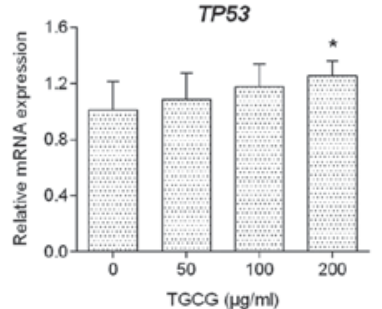

CDK4

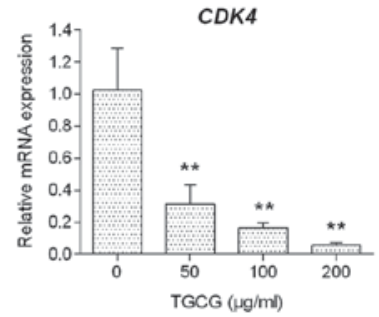

CCND1

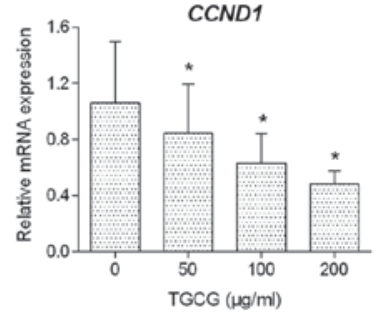

$B A X$

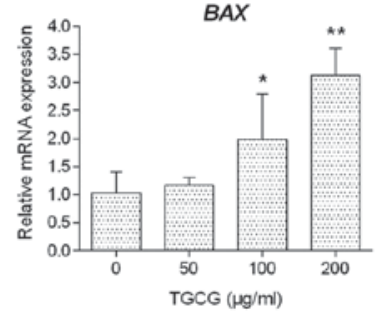

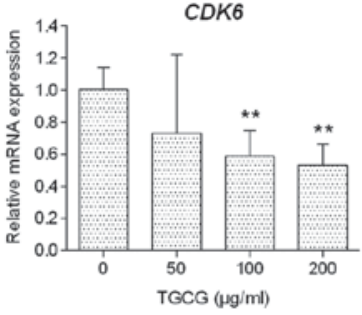

MDM 2
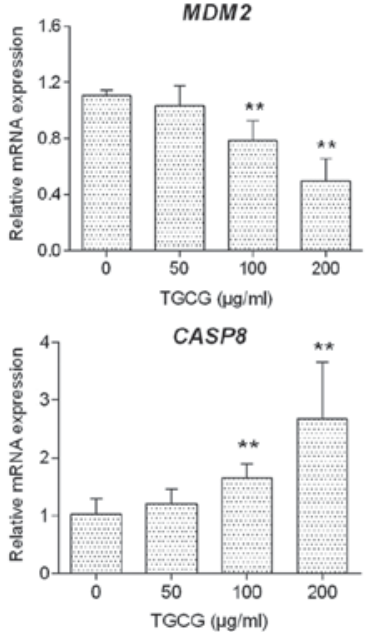
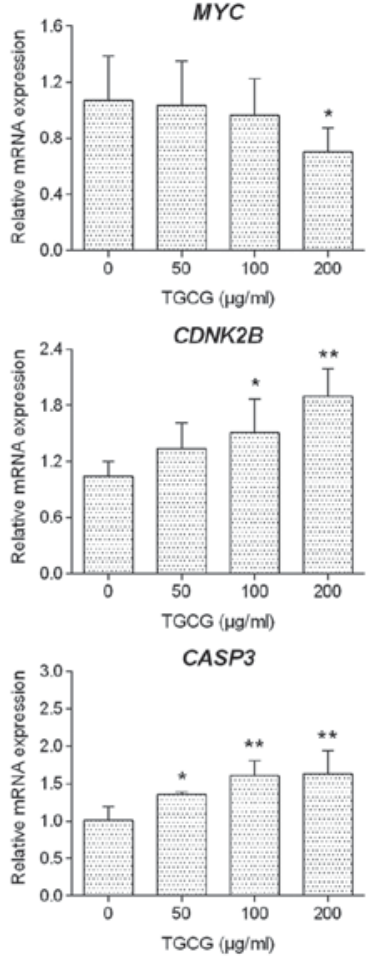

Figure 5. Relative mRNA expression of target genes in HT-29 cells following $24 \mathrm{~h}$ TGCG treatment. Values are presented as the mean \pm standard deviation. ${ }^{*} \mathrm{P}<0.05$ and ${ }^{* *} \mathrm{P}<0.01$ vs. the untreated group $(0 \mu \mathrm{g} / \mathrm{ml})$. TGCG, total ginsenosides of Chinese ginseng; Cdk, cyclin-dependent kinase.

and attenuate nausea and vomiting induced by chemotherapeutics, indicating an effect-enhancing and toxicity-reducing activity (40-42). 5-FU is a key drug that causes perturbation of ribosome biogenesis in CRC cells by activating ribosomal proteins and p21, leading to p21-mediated cell cycle arrest and apoptosis $(43,44)$. It is known that c-Myc is a key regulator of ribosome biogenesis and emerging data indicate that 5-FU induces apoptosis through ribosomal protein-mediated regulation of $\mathrm{NF}-\kappa \mathrm{B}$. In this study, TGCG has been shown to function on $\mathrm{c}-\mathrm{Myc}$ and $\mathrm{p} 21$, thereby indicating a possible mechanism that TGCG regulates c-Myc expression to activate p21/ribosomal protein and leads to cell cycle arrest of CRC.

It was also found that TGCG induced cell apoptosis of CRC by activating p53-mediated apoptotic pathway where TOP1 and $M D M 2$ were downregulated and TP53, BAX, CASP3, and CASP8 were upregulated. TOPI encodes DNA topoisomerase I for DNA repair during DNA synthesis and meiotic division. It is highly expressed in cancer cells making transient single-strand DNA 


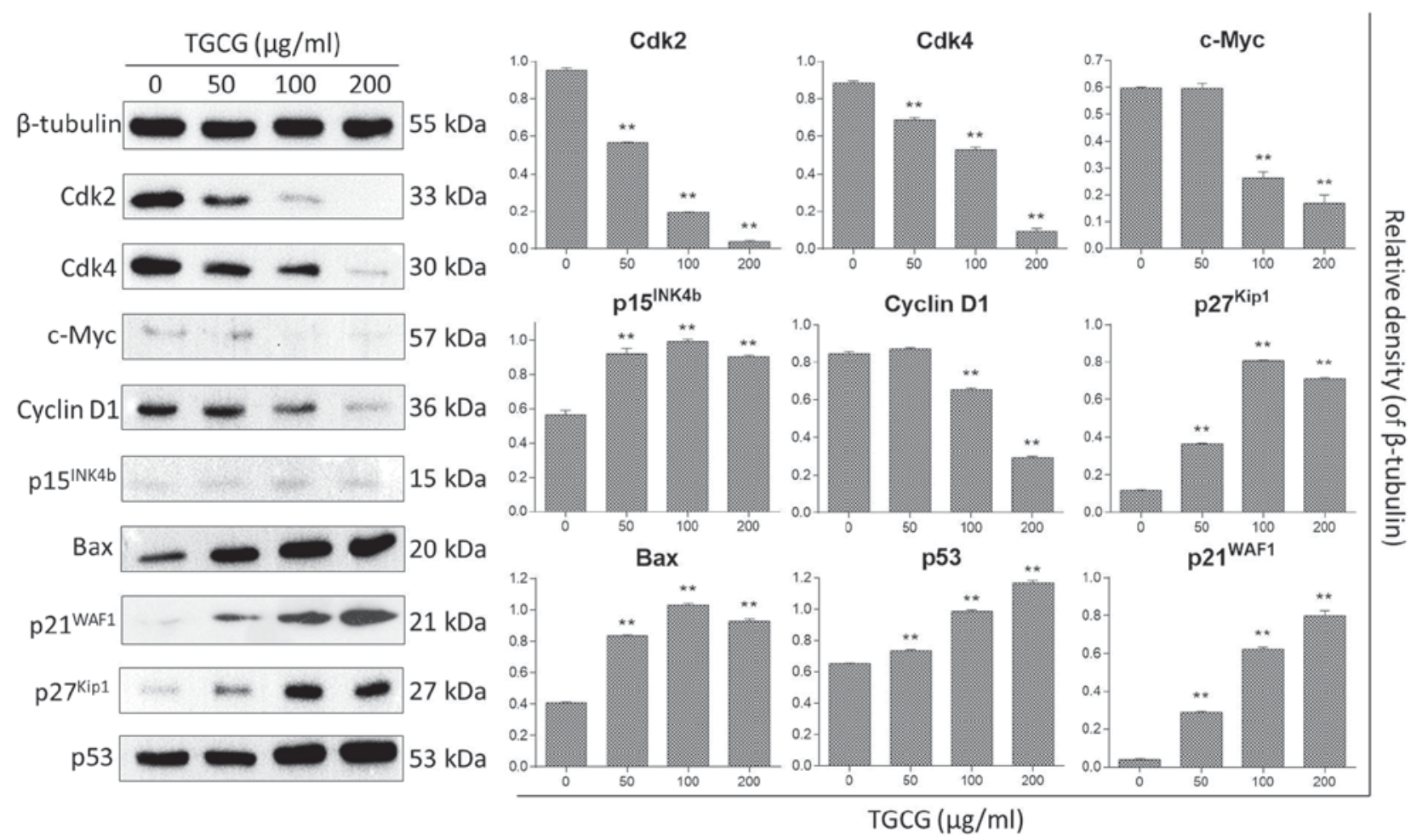

Figure 6. Western blot analysis was performed to measure protein expression in HT-29 cells following $24 \mathrm{~h}$ TGCG treatment. Values are presented as the mean \pm standard devaiton. ${ }^{* *} \mathrm{P}<0.01$ vs. the untreated group $(0 \mu \mathrm{g} / \mathrm{ml})$. TGCG, total ginsenosides of Chinese ginseng; Cdk, cyclin-dependent kinase.

breaks to solve topological problems of DNA, while DNA strand breaks (DSBs) formed with inhibition of its expression (45). DSBs can trigger DNA damage with induction of apoptosis in cancer cells (46), which might be an initial event in the action of TGCG. TP53 encodes the tumor suppressor p53 that can be activated in response to DNA damage. It is a crucial transcription factor responsible for the prevention of cancer formation due to its role in conserving stability of genome (47). When DNA suffers irreparable damage, p53 can bind DNA and initiate cell apoptosis, which in turn activates transcription of many apoptotic genes, including the members of Bcl-2 family (e.g., $B A X$ ) and caspase family (e.g., CASP3 and CASP8) (48). However, the transcriptional activity of p53 can be inhibited by an E3 ubiquitin ligase (Mdm2) encoded by MDM2. Mdm2 is a negative regulator of p53 and is always overexpressed in tumor cells, which would shuttle p53 out of the nucleus and terminate p53-mediated apoptosis (49). In this study, TGCG activated p53 and inhibited $M D M 2$ expression to induce cell apoptosis following activation of p53-downstreamed target genes (BAX, CASP3 and CASP8). Bax functions as an apoptosis activator tending to interact with mitochondria and release cytochrome $c$ and pro-apoptotic factors to activate caspases (50). Caspase- 8 encoded by CASP 8 plays an initial role in the caspase cascade which activates execution-phase of cell apoptosis. Overexpression of CASP8 induces apoptotic cell death in tumor cells, and it most likely acts upon caspase-3. Caspase- 3 encoded by $C A S P 3$ acts as the predominant 'executioner caspase' in apoptotic cell death. It can be activated in the apoptotic cells both by extrinsic (death ligand) and intrinsic (mitochondrial) pathways (51).

Taken together, our results indicate that TGCG induced cell cycle arrest at $\mathrm{G}_{0} / \mathrm{G}_{1}$ and $\mathrm{G}_{2} / \mathrm{M}$ phases and apoptosis in HT-29 cells via c-Myc- and p53-associated mechanism, respectively, possibly in response to DNA damage. Recently, increasing studies have been focused on the anti-CRC activity of the single compound of Chinese ginseng and obtained positive outcomes. We found that TGCG exerted stronger anti-CRC effect than that of each compound of Chinese ginseng (Rb1, $\mathrm{Re}, \mathrm{Rd}$, and Rg1), indicating a synergistic action of those compounds in TGCG. It makes TGCG a promising candidate for anti-CRC application and drug development due to its better effect, easier preparation procedure, and lower cost.

\section{Acknowledgements}

Not applicable.

\section{Funding}

The present study was funded by the Zhejiang Provincial Natural Science Foundation of China (grant nos. LY17H270001 and LY17H270016), the Major Science and Technology Special Project of Zhejiang Province (grant no. 2014C03035), the National Natural Science Foundation of China (grant no. 81673997), the Zhejiang Provincial Major Science and Technology Project of Medical and Health of China (grant no. 201487674) and the Zhejiang Provincial Science and Technology Project of Traditional Chinese Medicine of China (grant nos. 2015ZA193, 2013ZB098, 2016ZZ011, 2016ZQ010, and 2013ZQ007).

\section{Availability of data and materials}

The datasets used and/or analyzed during the current study are available from the corresponding author on reasonable request. 


\section{Authors' contributions}

TL and WS were the principal scientists conducted the experiments. XD, WY and JC assisted with the experiments. LS and QY conceived, designed and revised the study and drafted the manuscript. TE made substantial contributions to the experimental design and revised the manuscript.

\section{Ethics approval and consent to participate}

Not applicable.

\section{Patient consent for publication}

Not applicable.

\section{Competing interests}

The authors declare that they have no competing interests.

\section{References}

1. Siegel RL, Miller KD and Jemal A: Cancer statistics, 2015. CA Cancer J Clin 65: 5-29, 2015.

2. Ferlay J, Soerjomataram I, Dikshit R, Eser S, Mathers C, Rebelo M, Parkin DM, Forman D and Bray F: Cancer incidence and mortality worldwide: Sources, methods and major patterns in GLOBOCAN 2012. Int J Cancer 136: E359-E386, 2015.

3. Kolligs FT: Diagnostics and epidemiology of colorectal cancer. Visc Med 32: 158-164, 2016.

4. Center MM, Jemal A and Ward E: International trends in colorectal cancer incidence rates. Cancer Epidemiol Biomarkers Prev 18: 1688-1694, 2009.

5. Platz EA, Willett WC, Colditz GA, Rimm EB, Spiegelman D and Giovannucci E: Proportion of colon cancer risk that might be preventable in a cohort of middle-aged US men. Cancer Causes Control 11: 579-588, 2000.

6. Baak JP, Gyllenhaal C, Liu L, Guo H and Block KI: Prognostic proof and possible therapeutic mechanisms of herbal medicine in patients with metastatic lung and colon cancer. Integr Cancer Ther 10: NP1-NP11, 2011.

7. Mano MS and Duhoux F: Colon cancer: Update on adjuvant therapy. Clin Colorectal Cancer 7: 178-183, 2008.

8. Iwamoto T: Clinical application of drug delivery systems in cancer chemotherapy: Review of the efficacy and side effects of approved drugs. Biol Pharm Bull 36: 715-718, 2013.

9. Ades S: Adjuvant chemotherapy for colon cancer in the elderly: Moving from evidence to practice. Oncology (Williston Park) 23 162-167, 2009.

10. Martin AR, Carides AD, Pearson JD, Horgan K, Elmer M, Schmidt C, Cai B, Chawla SP and Grunberg SM: Functional relevance of antiemetic control. Experience using the FLIE questionnaire in a randomised study of the NK-1 antagonist aprepitant. Eur J Cancer 39: 1395-1401, 2003.

11. Chien TJ, Liu CY, Lu RH, Kuo CW, Lin YC and Hsu CH: Therapeutic efficacy of Traditional Chinese medicine, 'Kuan-Sin-Yin', in patients undergoing chemotherapy for advanced colon cancer-A controlled trial. Complement Ther Med 29: 204-212, 2016.

12. Lin YY, Lee IY, Huang WS, Lin YS, Kuan FC, Shu LH, Cheng YC, Yang YH and Wu CY: Danshen improves survival of patients with colon cancer and dihydroisotanshinone I inhibit the proliferation of colon cancer cells via apoptosis and skp2 signaling pathway. J Ethnopharmacol 209: 305-316, 2017

13. Su Z, Zhou C, Qin S, Jia E and Wu Z: The significant pathways and genes underlying the colon cancer treatment by the traditional Chinese medicine PHY906. Evid Based Complement Alternat Med 2017: 8753815, 2017.

14. Wang J, Li XM, Bai Z, Chi BX, Wei Y and Chen X: Curcumol induces cell cycle arrest in colon cancer cells via reactive oxygen species and Akt/GSK3ß/cyclin D1 pathway. J Ethnopharmacol 210: 1-9, 2018.
15. Lin H, Liu J and Zhang Y: Developments in cancer prevention and treatment using traditional Chinese medicine. Front Med 5: 127-133, 2011.

16. Baeg IH and So SH: The world ginseng market and the ginseng (Korea). J Ginseng Res 37: 1-7, 2013.

17. Dai D, Zhang CF, Williams S, Yuan CS and Wang CZ: Ginseng on cancer: Potential role in modulating inflammation-mediated angiogenesis. Am J Chin Med 45: 13-22, 2017.

18. Wang CZ, Zhang Z, Wan JY, Zhang CF, Anderson S, He X, Yu C, He TC, Qi LW and Yuan CS: Protopanaxadiol, an active ginseng metabolite, significantly enhances the effects of fluorouracil on colon cancer. Nutrients 7: 799-814, 2015.

19. Lee JG, McKinney KQ, Pavlopoulos AJ, Park JH and Hwang S: Data supporting the identification of anti-metastatic drug and natural compound targets in isogenic colorectal cancer cells. Data Brief 1: 73-75, 2014

20. Wang CZ, Xie JT, Zhang B, Ni M, Fishbein A, Aung HH, Mehendale SR, Du W, He TC and Yuan CS: Chemopreventive effects of Panax notoginseng and its major constituents on SW480 human colorectal cancer cells. Int J Oncol 31: 1149-1156, 2007.

21. Zhu C, Liu F, Qian W, Zhang T and Li F: Combined effect of sodium selenite and ginsenoside Rh2 on HCT116 human colorectal carcinoma cells. Arch Iran Med 19: 23-29, 2016.

22. Lee JG, McKinney KQ, Pavlopoulos AJ, Park JH and Hwang S: Identification of anti-metastatic drug and natural compound targets in isogenic colorectal cancer cells. J Proteomics 113: 326-336, 2015.

23. Chen L, Meng Y, Sun Q, Zhang Z, Guo X, Sheng X, Tai G, Cheng $\mathrm{H}$ and Zhou Y: Ginsenoside compound $\mathrm{K}$ sensitizes human colon cancer cells to TRAIL-induced apoptosis via autophagy-dependent and -independent DR5 upregulation. Cell Death Dis 7: e2334, 2016.

24. Tang QY and Feng MG: DPS data processing system: Experimental design, statistical analysis and data mining. Beijing Science Press, Beijing, China, 2007.

25. Yun TK, Choi SY and Yun HY: Epidemiological study on cancer prevention by ginseng: Are all kinds of cancers preventable by ginseng? J Korean Med Sci 16 (Suppl): S19-S27, 2001.

26. Cheng H, Li S, Fan Y, Gao X, Hao M, Wang J, Zhang X, Tai G and Zhou Y: Comparative studies of the antiproliferative effects of ginseng polysaccharides on HT-29 human colon cancer cells. Med Oncol 28: 175-181, 2011.

27. Li B, Wang CZ, He TC, Yuan CS and Du W: Antioxidants potentiate American ginseng-induced killing of colorectal cancer cells. Cancer Lett 289: 62-70, 2010.

28. Kim SE, Lee YH, Park JH and Lee SK: Ginsenoside-Rs4, a new type of ginseng saponin concurrently induces apoptosis and selectively elevates protein levels of p53 and p21WAF1 in human hepatoma SK-HEP-1 cells. Eur J Cancer 35: 507-511, 1999.

29. Choi S, Kim TW and Singh SV: Ginsenoside Rh2-mediated G1 phase cell cycle arrest in human breast cancer cells is caused by p15 Ink4B and p27 Kip1-dependent inhibition of cyclin-dependent kinases. Pharm Res 26: 2280-2288, 2009.

30. Gao JL, Lv GY, He BC, Zhang BQ, Zhang H, Wang N, Wang CZ, $\mathrm{Du}$ W, Yuan CS and He TC: Ginseng saponin metabolite 20(S)-protopanaxadiol inhibits tumor growth by targeting multiple cancer signaling pathways. Oncol Rep 30: 292-298, 2013.

31. Park HM, Kim SJ, Kim JS and Kang HS: Reactive oxygen species mediated ginsenoside Rg3- and Rh2-induced apoptosis in hepatoma cells through mitochondrial signaling pathways. Food Chem Toxicol 50: 2736-2741, 2012.

32. Zhang Z, Li Z, Wu X, Zhang CF, Calway T, He TC, Du W, Chen J, Wang CZ and Yuan CS: TRAIL pathway is associated with inhibition of colon cancer by protopanaxadiol. J Pharmacol Sci 127: 83-91, 2015.

33. Dang CV: c-Myc target genes involved in cell growth, apoptosis, and metabolism. Mol Cell Biol 19: 1-11, 1999.

34. Grandori C, Cowley SM, James LP and Eisenman RN: The Myc/Max/Mad network and the transcriptional control of cell behavior. Annu Rev Cell Dev Biol 16: 653-699, 2000.

35. Shao Q, Kannan A, Lin Z, Stack BC Jr, Suen JY and Gao L: BET protein inhibitor JQ1 attenuates Myc-amplified MCC tumor growth in vivo. Cancer Res 74: 7090-7102, 2014.

36. Gu J, Cui CF, Yang L, Wang L and Jiang XH: Emodin inhibits colon cancer cell invasion and migration by suppressing epithelialmesenchymal transition via the Wnt/ $\beta$-catenin pathway. Oncol Res: Jan 4, 2018 (Epub ahead of print).

37. Chen Y,Jiang J,ZhaoM,LuoX,LiangZ,Zhen Y,Fu Q,Deng X,Lin X, Li L, et al: microRNA-374a suppresses colon cancer progression by directly reducing CCND1 to inactivate the PI3K/AKT pathway. Oncotarget 7: 41306-41319, 2016. 
38. Izutani Y, Yogosawa S, Sowa Y and Sakai T: Brassinin induces G1 phase arrest through increase of p21 and p27 by inhibition of the phosphatidylinositol 3-kinase signaling pathway in human colon cancer cells. Int J Oncol 40: 816-824, 2012.

39. Yang Z, Li C, Wang X, Zhai C, Yi Z, Wang L, Liu B, Du B, Wu H, Guo X, et al: Dauricine induces apoptosis, inhibits proliferation and invasion through inhibiting NF-kappaB signaling pathway in colon cancer cells. J Cell Physiol 225: 266-275, 2010.

40. Mehendale S, Aung H, Wang A, Yin JJ, Wang CZ, Xie JT and Yuan CS: American ginseng berry extract and ginsenoside Re attenuate cisplatin-induced kaolin intake in rats. Cancer Chemother Pharmacol 56: 63-69, 2005.

41. Fishbein AB, Wang CZ, Li XL, Mehendale SR, Sun S, Aung HH and Yuan CS: Asian ginseng enhances the anti-proliferative effect of 5-fluorouracil on human colorectal cancer: Comparison between white and red ginseng. Arch Pharm Res 32: 505-513, 2009.

42. Gu C, Qiao J, Zhu M, Du J, Shang W, Yin W, Wang W, Han M and $\mathrm{Lu} \mathrm{W}$ : Preliminary evaluation of the interactions of Panax ginseng and Salvia miltiorrhiza Bunge with 5-fluorouracil on pharmacokinetics in rats and pharmacodynamics in human cells. Am J Chin Med 41: 443-458, 2013.

43. Pagliara V, Saide A, Mitidieri E, d'Emmanuele di Villa Bianca R, Sorrentino R, Russo G and Russo A: 5-FU targets rpL3 to induce mitochondrial apoptosis via cystathionine- $\beta$-synthase in colon cancer cells lacking p53. Oncotarget 7: 50333-50348, 2016.

44. Russo A, Saide A, Cagliani R, Cantile M, Botti G and Russo G: rpL3 promotes the apoptosis of p53 mutated lung cancer cells by down-regulating $\mathrm{CBS}$ and $\mathrm{NF} \kappa \mathrm{B}$ upon 5-FU treatment. Sci Rep 6: 38369, 2016.

45. Holden JA: DNA topoisomerases as anticancer drug targets: From the laboratory to the clinic. Curr Med Chem Anti-Canc Agents 1: 1-25, 2001.
46. Cheng MH, Yang YC, Wong YH, Chen TR, Lee CY, Yang CC, Chen SH, Yang IN, Yang YS, Huang HS, et al: B1, a novel topoisomerase II inhibitor, induces apoptosis and cell cycle G1 arrest in lung adenocarcinoma A549 cells. Anticancer Drugs 23: 191-199, 2012.

47. Surget S, Khoury MP and Bourdon JC: Uncovering the role of p53 splice variants in human malignancy: A clinical perspective. Onco Targets Ther 7: 57-68, 2013.

48. Levine AJ and Oren M: The first 30 years of $\mathrm{p} 53$ : Growing ever more complex. Nat Rev Cancer 9: 749-758, 2009.

49. Wang X, Arooz T, Siu WY, Chiu CH, Lau A, Yamashita K and Poon RY: MDM2 and MDMX can interact differently with ARF and members of the p53 family. FEBS Lett 490: 202-208, 2001.

50. Weng C, Li Y, Xu D, Shi Y and Tang H: Specific cleavage of Mcl-1 by caspase-3 in tumor necrosis factor-related apoptosis-inducing ligand (TRAIL)-induced apoptosis in Jurkat leukemia T cells. J Biol Chem 280: 10491-10500, 2005.

51. Salvesen GS: Caspases: Opening the boxes and interpreting the arrows. Cell Death Differ 9: 3-5, 2002. 